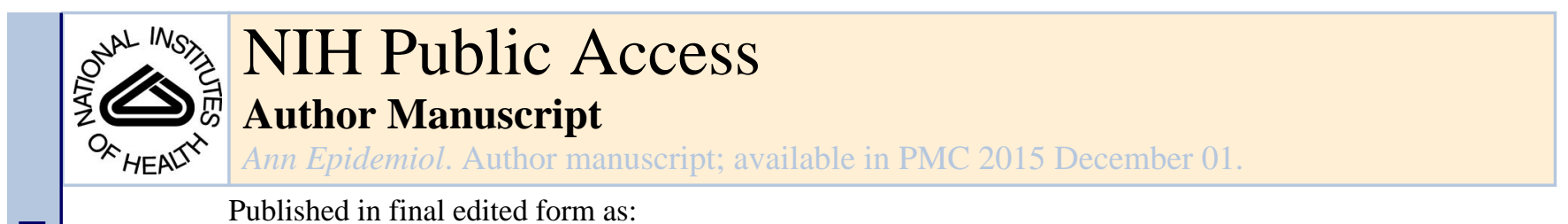

Published in final edited form as:

Ann Epidemiol. 2014 December ; 24(12): 903-909.e1. doi:10.1016/j.annepidem.2014.09.010.

\title{
Blood spot-based measures of glucose homeostasis and diabetes prevalence in a nationally representative population of young U.S. adults
}

Quynh C. Nguyen, PhD ${ }^{a, b}$, Eric A. Whitsel, MD MPH ${ }^{b, c}$, Joyce W. Tabor, MS ${ }^{d}$, Carmen C. Cuthbertson, MCN ${ }^{b, d}$, Mark H. Wener, MD ${ }^{e}$, Alan J. Potter, PhD ${ }^{e}$, Carolyn T. Halpern, PhD ${ }^{d, f}$, Ley A Killeya-Jones, $\mathbf{P h D}^{\mathrm{d}}$, Jon M. Hussey, $\mathbf{P h D}^{\mathrm{d}, \mathrm{f}}$, Chirayath Suchindran, $\mathbf{P h D}{ }^{g}$, and Kathleen Mullan Harris, $\mathbf{P h D}^{\mathrm{d}} \mathrm{h}$

bDepartment of Epidemiology, UNC Gillings School of Global Public Health

'Department of Medicine, University of North Carolina at Chapel Hill

${ }^{d}$ Carolina Population Center, University of North Carolina at Chapel Hill

eDepartment of Laboratory Medicine, University of Washington School of Medicine

fDepartment of Maternal and Child Health, UNC Gillings School of Global Public Health

gDepartment of Biostatistics, UNC Gillings School of Global Public Health

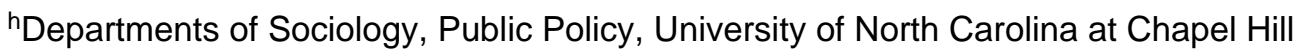

Abstract

Purpose-We investigated under-studied, biomarker-based diabetes among young U.S. adults, traditionally characterized by low cardiovascular disease risk.

\begin{abstract}
Methods-We examined 15,701 participants aged 24-32 years at Wave IV of the National Longitudinal Study of Adolescent Health (Add Health, 2008). The study used innovative and relatively non-invasive methods to collect capillary whole blood via finger prick at in-home examinations in all fifty states.
\end{abstract}

Results-Assays of dried blood spots produced reliable and accurate values of $\mathrm{HbA1c}$. Reliability was lower for fasting glucose and lowest for random glucose. Mean (standard deviation) HbA1c was 5.6\% (0.8\%). More than a quarter (27.4\%) had HbA1c-defined prediabetes. HbA1c was highest in the black, non-Hispanic race/ethnic group; inversely associated with education; and more common among the overweight/obese, and physically inactive. The prevalence of diabetes defined by previous diagnosis or use of anti-diabetic medication was $2.9 \%$.

(C) 2014 Elsevier Inc. All rights reserved.

CORRESPONDENCE TO: Quynh C Nguyen, Department of Health Promotion and Education, University of Utah, 1901 E. South Campus Drive, Annex Room 2124, Salt Lake City UT 84112, Tel: (801) 585-5134; Fax: (801) 585-3646; quynh.nguyen@ health.utah.edu.

aPresent address: Department of Health Promotion and Education, College of Health, University of Utah;

Publisher's Disclaimer: This is a PDF file of an unedited manuscript that has been accepted for publication. As a service to our customers we are providing this early version of the manuscript. The manuscript will undergo copyediting, typesetting, and review of the resulting proof before it is published in its final citable form. Please note that during the production process errors may be discovered which could affect the content, and all legal disclaimers that apply to the journal pertain. 
Further incorporating $\mathrm{HbA} 1 \mathrm{c}$ and glucose values, the prevalence increased to $6.8 \%$, and among these participants, $38.9 \%$ had a previous diagnosis of diabetes (i.e., aware). Among those aware, $37.6 \%$ were treated and $64.0 \%$ were controlled (i.e., HbA1c $<7 \%$ ).

Conclusions-A contemporary cohort of young adults faces a historically high risk of diabetes but there is ample opportunity for early detection and intervention.

\section{Keywords}

HbA1c; Glucose; Diabetes Mellitus; Young Adult; Health Surveys; Dried Blood Spot Testing

In 2012, economic costs of diagnosed diabetes totaled \$245 billion, including \$176 billion in direct medical costs and $\$ 69$ billion in reduced productivity (1). The 2012 economic burden represents a $41 \%$ increase from $\$ 174$ billion in 2007 . The largest components of medical expenditures for diabetes include hospital inpatient care (43\%) and prescription medications for diabetes complications (18\%). Type 2 diabetes onset at age 20 is associated with a 15year reduction in life expectancy, increased risk of severe, chronic diabetes complications by age 40, and worse education attainment and employment outcomes $(2,3)$. As such, diabetes in the first few decades of life is clinically, economically and societally burdensome (3-6).

However, little is known about diabetes prevalence in contemporary populations of young adults in the United States, traditionally characterized by low cardiovascular disease risk. Given that $28 \%$ of the US population is unaware of their diabetes, exam-based assessments such as those from the National Health and Nutrition Examination Survey (NHANES) provide valuable information on the full burden of diabetes (7-10). Besides NHANES, to our knowledge, the National Longitudinal Study of Adolescent Health (Add Health) is the only other study from which it is possible to estimate biomarker-based prevalence of diabetes among contemporary U.S. young adults in their twenties.

Add Health—widely used in social, behavioral, and health science research (11)—is notable for its national probability sampling strategy, oversampling of typically underrepresented groups, and high response rate. Add Health is uniquely suited for examinations of the transition to adulthood. The larger sample of young adults (15-20 times the size of one NHANES cohort of young adults) enables potentially more precise estimates and comprehensive analysis of subgroup differences (e.g., incorporating finer racial/ethnic categorizations) (12-14). Additionally, the measurement of diabetes in field studies such as Add Health is distinct from and potentially more complicated than that in examination center-based studies, requiring adaptation of biomarker collection to more variable home environments and utilizing many more field staff.

In Add Health, measures of glucose homeostasis were obtained via an innovative and relatively non-invasive collection of capillary whole blood via finger prick. While these relatively recently developed methods of evaluating glucose homeostasis have been used in the Moving to Opportunity (MTO) housing experiment, Health and Retirement Study (HRS), National Social Life, Health, and Aging Project (NSHAP), and Los Angeles Family and Neighborhood Survey (LAFANS), little information is available on the validity and reliability of the measurements they generate (15-17). We therefore examined these 
properties in the larger Add Health sample. Addressing gaps in the literature, the objectives of this study are to: first assess the quality of measures of glucose homeostasis derived from dried blood spot technology, and then to quantify diabetes prevalence overall and by important demographic, social, clinical and behavioral risk factors, thereby allowing assessments of health disparities.

\section{METHODS}

\section{Add Health study design and data collection}

Add Health enrolled a national probability sample of 20,745 U.S. adolescents in grades 7 through 12 during the 1994-1995 school year (Wave I response rate: 79\%) (18). The Add Health cohort has been followed for over a 13-year period and represents over 22 million individuals. Three in-home follow-up interviews have been completed: Wave II in 1996 (88\% of the eligible cohort at Wave I), Wave III in 2001-2002 (77\%), and Wave IV in 2008 $(80 \%)$. Each wave of the study was approved by the University of North Carolina Public Health-Nursing Institutional Review Board (Chapel Hill, NC).

Detailed information on Add Health's measures of glucose homeostasis has been published elsewhere (19). Briefly, all 15,701 Wave IV Add Health participants were asked whether a health care professional ever told them they had high blood sugar or diabetes (i.e., selfreported history of diabetes). Women were asked to exclude diagnoses during pregnancy. Anti-diabetic medication use within the preceding four weeks was inventoried by visually inspecting participant-assembled medication containers and categorizing their contents in real-time using Lexicon Plus ${ }^{\mathrm{TM}}$ (Lexi-Comp®, Inc.; Hudson, OH).

Capillary whole blood was collected via finger prick from voluntarily fasting ( $\geq 8$ hours) and non-fasting participants onto seven-spot, Whatman 903® Protein Saver cards by trained and certified field interviewers, subjected to in situ desiccation, then shipped to FlexSite Diagnostics, Inc. (Palm City, FL) for assay of HbA1c (\%), and to the University of Washington Department of Laboratory Medicine (Seattle, WA) for assay of glucose (mg/dl). The analytical sensitivity, within- and between-assay coefficients of variation were $3.0 \%$, $2.2 \%$ and $2.4 \%$ for $\mathrm{HbA} 1 \mathrm{c}$ and $22 \mathrm{mg} / \mathrm{dl}, 4.4 \%$, and $4.8 \%$ for glucose. In paired whole blood and blood spots $(n=80)$, HbA1c values were strongly associated (Pearson $r=0.99)$. Associations in paired serum and blood spots $(\mathrm{n}=83)$ were equally strong for glucose concentrations (Pearson $r=0.97$ ).

Test-retest reliability analysis in Add Health-In a quality control study conducted over the course of field work, the short-term retest reliability of HbA1c and glucose was assessed in a race/ethnicity- and sex-stratified random sample of 100 Add Health Wave IV participants (mean age 29 years; 50\% female; 64\% non-Hispanic White; $16 \%$ non-Hispanic Black; $12 \%$ Hispanic/Latino; $8 \%$ other) examined twice, one to two weeks (mean: 8.6 days) apart. At the two examinations, biospecimens were collected typically by the same field interviewer (84\% of participants) and at approximately the same time of day (mean | difference|: 52 minutes; range 0-302 minutes). 
The variance in measures of HbA1c (and separately, glucose) was partitioned in a random effects model by letting $Y_{i j}$ be the measure on the $\mathrm{i}^{\text {th }}$ participant at the $\mathrm{j}^{\text {th }}$ visit: $Y_{i j}=\mu$ $+P_{i}+m_{j(i)}+e_{i j}$, where $\mu$ is the sample mean and $P_{i,} m_{j(i)}$, and $e_{i j}$ are the normally distributed participant, measurement, and error effects with mean zero and variance $\sigma_{p}^{2}, \sigma_{m}^{2}$, and $\sigma_{e}^{2}$, respectively. Assuming the variance components are independently distributed, the total variance of $\mathrm{Y}\left(\sigma_{T}^{2}\right)$ is: $\sigma_{T}^{2}=\sigma_{p}^{2}+\sigma_{m}^{2}+\sigma_{e}^{2}$. Reliability was then estimated as the ratio of the between-participant to total variance: $\sigma_{p}^{2} / \sigma_{T}^{2}$, i.e. an intraclass correlation coefficient (ICC) with 95\% confidence intervals estimated using the delta method (20). The ICC represents the proportion of variance not due to measurement variance. Random effects models were implemented in SAS® 9.1 using Proc Mixed and the restricted maximum likelihood method.

Validity analysis in Add Health-In a separate quality control study conducted over ten weeks of field work, a dried blood spot (DBS) from each of three donors was shipped twice weekly to FlexSite Diagnostics, Inc. ("Lab A") and assayed by laboratory staff masked to the origin of the samples. The 60 returned values of $\mathrm{HbA} 1 \mathrm{c}$ were compared to values of HbA1c conventionally assayed in paired whole blood from the same donors on a G7 Automated HPLC-HbA1c Analyzer (Tosoh Bioscience, Inc., San Francisco, CA) by Duke University Health System Laboratories (Durham, NC) ("Lab B"). Accuracy was computed as the Lab A minus Lab B difference (bias, \%) and its ratio with respect to the criterion standard (relative bias $=100 \times$ bias $/$ Lab B).

\section{Identification of diabetes and its medical management}

Diabetes was identified by incorporating self-reported history, anti-diabetic medication use, and abnormality of $\mathrm{HbAlc}$ and/or glucose identified by American Diabetes Association (ADA) diagnostic thresholds (21): (1) HbA1c $\geq 6.5 \%$, (2) non-fasting glucose $\geq 200 \mathrm{mg} / \mathrm{dl}$, and/or (3) fasting glucose $\geq 126 \mathrm{mg} / \mathrm{dl}$. Pre-diabetes $(\mathrm{HbAlc}=5.7-6.4 \%)$ also was identified. Among those with diabetes, awareness was defined as reporting a previous diagnosis. Among those aware, treatment was defined as taking anti-diabetic medications and control of diabetes was defined as HbA1c <7\%, according to ADA guidelines (22).

Covariates-Subgroups were defined by the following characteristics: sex (male, female), race/ethnicity (non-Hispanic whites, blacks, and Asian/Pacific Islanders, other race/ multiracial, Mexican-American, other Hispanic), education (0-11 years, high school graduate/GED, some college/Associate's degree, 4-year college) as well as foreign birth, insurance status, history of diabetes, use of anti-diabetic medication, and fasting $\geq 8$ hours. Body mass index (BMI kg/ $\mathrm{m}^{2}$ ) categories included: underweight/normal (<18.5-24.9); overweight (25.0-29.9); obese class I (30-34.9): obese class II/III ( $\geq 35.0)$. Central obesity was defined as waist circumference $>102 \mathrm{~cm}$ (men) or $>88 \mathrm{~cm}$ (women, excluding pregnant women) (23). Fast food intake was assessed via past-7 day frequency of eating from a fast food restaurant ( $0, \leq 2$ times, $\geq 3$ times). Binge drinking was assessed via frequency of $\geq 5$ (men) or $\geq 4$ (women) drinks in a row (none, less than weekly, weekly). Cigarette smoking was assessed by past-30 day smoking frequency (none, less than daily, daily) (24-26). Moderate to vigorous recreational physical activity was defined as the 
number of times in the past seven days participants engaged in various physical activities ( $\geq$ 5 times, 1-4 times, none) (27), assessed by summing responses to seven questions (e.g., "In the past seven days, how many times did you roller blade, roller skate, downhill ski, snow board, play racquet sports, or do aerobics?"). Measurement session was categorized as morning (8:30am), afternoon (1:30pm), and evening (5:30pm).

Analyses of HbA1c and glucose utilized data from 13,465 and 13,112 participants aged 2432 years with non-missing survey weights and assay results. Summary statistics were estimated using STATA®/SE 10 software (StataCorp LP, College Station, TX), accounting for the clustered design and using sample weights to adjust for unequal probability of selection and attrition, to produce nationally representative estimates.

\section{RESULTS}

In our analysis sample, the mean age of participants was 28 years and approximately half were female (Table 1). Two-thirds were white, with large proportions of blacks (14\%) and Hispanics (11\%). Results of our quality control studies suggest reliability was highest for HbA1c (ICC: 0.97), lower for fasting glucose (ICC: 0.66), and lowest for random glucose collected in the fasting or non-fasting state (ICC: 0.39) (Table 2). Within-participant coefficients of variation were $2.4 \%$ for $\mathrm{HbA} 1 \mathrm{c}, 13.5 \%$ for fasting glucose, and $17.5 \%$ for random glucose (Table 2). HbA1c was over-estimated by an average of $0.2 \%$ in dried blood spot testing compared to conventional whole blood assays, but relative bias did not exceed $5 \%$ (Table 3 ).

The prevalence of HbA1c-defined diabetes was 3.6\%. More than a quarter (27.4\%) had HbAlc-defined pre-diabetes (Table 4). HbA1c was highest in the black, non-Hispanic race/ ethnic group; inversely associated with education; and more common among participants with a history of diabetes or elevated fasting glucose, users of anti-diabetic medication, the overweight/obese, and the physically inactive. Participants were not asked to fast, and only $16 \%$ fasted. Among fasters, racial/ethnic minorities, obesity, history of diabetes, and use of anti-diabetic medications were over-represented when compared to the entire population (not shown). Therefore prevalence of non-fasting glucose $2200 \mathrm{mg} / \mathrm{dl}$ or fasting glucose $\geq$ $126 \mathrm{mg} / \mathrm{dl}$ was estimated: $2.5 \%$, overall (Table 5). Discernible patterns of variation in glucose with participant characteristics reflected those of $\mathrm{HbA1c}$, described above. Overall, $5.1 \%$ had either high $\mathrm{HbA1c}$ or high glucose (i.e., HbA1c $\geq 6.5$, fasting glucose $\geq 126$ $\mathrm{mg} / \mathrm{dl}$, or non-fasting glucose $\geq 200 \mathrm{mg} / \mathrm{dl}$ ) and among these participants, only $24.0 \%$ reported a previous diagnosis of diabetes.

The prevalence of diabetes defined by previous diagnosis or use of anti-diabetic medication was $2.9 \%$ (95\% CI: 2.5, 3.3) (Table 6). Further incorporating HbA1c and glucose values, the prevalence increased to $6.8 \%$, and among these, $38.9 \%$ had a previous diagnosis of diabetes (i.e., aware). Among those aware, $37.6 \%$ were taking anti-diabetic medication (i.e., treated), and $64.0 \%$ had $\mathrm{HbA} 1 \mathrm{c}<7 \%$ (i.e., controlled).

Supplemental analyses compared diabetes prevalence in Add Health with similarly aged adults (24-32 years) in NHANES 2007-2008 (see Appendix A for details on NHANES 
study design and cross-survey analyses). In NHANES, prevalence of diabetes incorporating self-reported history, anti-diabetic medication use, fasting glucose and $\mathrm{HbA1c}$ was $2.6 \%$ $(n=294)$. Compared with NHANES, participants in Add Health were less likely to be foreign-born, uninsured, and have less than a high school education, and more likely to be obese (not shown). Between survey differences were attenuated after controlling for age, sex, race/ethnicity, foreign-birth, education, health insurance, BMI status, central obesity, fast food intake, physical activity, cigarette use, and heavy drinking; Add Health vs. NHANES adjusted risk ratio: 1.7 (95\% CI: 0.8, 3.7).

\section{DISCUSSION}

We investigated the under-studied, biomarker-based prevalence of diabetes in a contemporary cohort of young U.S. adults by collecting capillary whole blood via finger prick and assaying HbA1c and glucose in dried blood spots (28). To put results in context, fasting plasma glucose has greater biological variability compared to $\mathrm{HbA1c}$ with coefficients of variation (CV) between 5-8\% vs. 1-2\%, respectively (29-31). Given biological variability, laboratory quality management standards designed to support informed medical decision-making suggest glucose analyses have desired analytic imprecision $\leq 2.3 \%$, bias $\leq 1.8 \%$, and total error $\leq 5.5 \%$ and that $\mathrm{HbAlc}(\%)$ analyses have imprecision, bias and total error $\leq 0.9 \%, 1.5 \%$, and $3.0 \%$, respectively (32). In this study, we found that $\mathrm{HbA} 1 \mathrm{c}$ values were highly reliable, minimally biased, and strongly correlated with fasting glucose. Analytic imprecision and bias of dried blood spot HbA1c approximated targeted analytic specifications derived from conventional clinical assays. Variability of glucose values from DBS slightly exceeded the range of previously reported estimates from conventional clinical analyses (33-35). However, glucose varied strikingly with participant characteristics related to well-known glucohomeostatic abnormalities, regardless of fasting status, and in doing so, mirrored blood spot-based HbA1c.

Next, we then turned to the identification of diabetes. The prevalence of HbAlc-defined prediabetes and diabetes was 27.4 and 3.6\%. After incorporating history of diabetes, antidiabetic medications, high $\mathrm{HbA1c}$, and high glucose, diabetes prevalence increased to $6.8 \%$, with only $38.9 \%$ reporting a previous diagnosis of diabetes (i.e., aware). Among those aware, $37.6 \%$ were treated with medications and $64.0 \%$ were controlled.

\section{Study findings in context}

In recent decades, minorities and economically disadvantaged groups have experienced the greatest rise in diabetes and worst outcomes from this disease (36-39). Between-group disparities in diabetes among young adults align with those found for all U.S adults. Agestandardized diabetes prevalence is higher among non-Hispanic blacks, Hispanics, and those of other/mixed races compared to Asians and non-Hispanic whites. Diabetes is also inversely correlated with education and income (40).

Typically studies utilizing dried blood spots technology to identify diabetes are conducted among populations of older adults. For instance, in the 2006 Health and Retirement Study of adults over the age of 50, diabetes (HbA1c $26.5 \%$ ) prevalence was 33\% among blacks, 37\% among Hispanics, and 17\% among whites (41). Comparable prevalence estimates are 
uncommon for younger U.S. adults at the forefront of the obesity epidemic. Moreover, diabetes is just one of many comorbidities that collectively foreshadow a future epidemic of chronic diseases among young people as they age (42-46). In Add Health among young adults, the prevalence of hypertension and obesity was $19 \%$ and $36 \%$, respectively $(47,48)$.

\section{Study strengths and limitations}

In a nationally representative field study, we investigated the quality of measures of glucose homeostasis and the prevalence of diabetes among young U.S. adults, traditionally characterized by low chronic disease risk. The study used innovative, cost-efficient, and relatively non-invasive methods to collect capillary whole blood via finger prick at in-home examinations in all fifty states. Add Health's in-home collection of biomarkers at Wave IV enables researchers to study what appear to be rising rates of chronic diseases among younger-aged groups in the United States (44-47). Moreover, reliable estimates of disease can be produced in Add Health for many groups underrepresented in other surveys.

However, our study has some limitations. Attrition may be of concern. Females, whites, and those with higher SES had higher response rates at Wave IV. Nonetheless, non-response biases are small across diverse measures of demographic characteristics, health and risk behaviors (49). Moreover, non-response at Wave IV was neither associated with risk of prediabetes nor undiagnosed diabetes predicted from demographic characteristics, SES, health behaviors, and health status (unpublished results, Anna Bellatorre, University of Nebraska). Importantly, in our analyses, we utilized survey weights to adjust for attrition.

The lack of a fasting requirement in Add Health meant that fasting glucose was available for only a non-representative subset of participants. A random glucose cut-point of $200 \mathrm{mg} / \mathrm{dl}$ is endorsed by the ADA for diabetes diagnosis and widely used in cohort studies such as the Framingham Heart Study and ARIC study $(22,50-52)$. However, it may have lower sensitivity than other detection methods. For example, previous studies found that random glucose values $\geq 160 \mathrm{mg} / \mathrm{dl}$ had a sensitivity of $44 \%$ and specificity of $96 \%$ (8) compared to fasting glucose $\geq 120 \mathrm{mg} / \mathrm{dl}$ which had a sensitivity of $67 \%$ specificity of $98 \%$, and $\mathrm{HbA} 1 \mathrm{c}$ $\geq 6.3 \%$ which had sensitivity of $40 \%$ sensitivity and specificity of $98 \%$ (53). Some have proposed utilizing random glucose to enable cost-efficient opportunistic screening of diabetes $(54,55)$. A study of a large health care system found that $70 \%$ of patients had a measure of glycemia in the past 3 years and $95 \%$ of these measurements were random glucose-likely due to routine inclusion of random glucose in standard chemistry panels (56). Alternatively, in this study, reliability of HbA1c was excellent and prevalence of diabetes estimated by $\mathrm{HbA1c} \geq 6.5 \%$ was available in both fasting and non-fasting populations. Advantages of $\mathrm{HbA1c}$ in identifying diabetes include convenience (no fasting requirement), greater pre-analytic stability, and ability to integrate exposure to hyperglycemia over the prior $2-3$ months $(57,58)$. However, HbA1c may have lower sensitivity than fasting glucose $(59,60)$. Also, guidelines for identifying diabetes recommend basing diagnoses on repeat testing, an approach unavailable in this research study (21). 


\section{Conclusions}

Diabetes is a growing problem in the United States with one study projecting that as many as one-third of adults could have diabetes in 2050 if trends persist (61). Low awareness of diabetes and the alarming rate of pre-diabetes among young adults suggest ample opportunity for early detection and intervention in a population often assumed to be unburdened by chronic conditions. National data from Add Health suggest that this cohort of young adults faces a historically high risk of cardiovascular disease, with higher than expected burden of diabetes as well as hypertension and obesity $(47,48)$. This finding is important because it may portend exponential growth in health issues and health care costs. Tackling disparities in the burden of chronic diseases, already apparent among young adults, is a critical endeavor.

\section{Acknowledgments}

FUNDING: This work was supported by the Eunice Kennedy Shriver National Institute of Child Health and Human Development (P01-HD31921), with cooperative funding from 23 other federal agencies and foundations.

This research uses data from Add Health, a program project directed by Kathleen Mullan Harris and designed by J. Richard Udry, Peter S. Bearman, and Kathleen Mullan Harris at the University of North Carolina at Chapel Hill, and funded by grant P01-HD31921 from the Eunice Kennedy Shriver National Institute of Child Health and Human Development, with cooperative funding from 23 other federal agencies and foundations. Special acknowledgment is due Ronald R. Rindfuss and Barbara Entwisle for assistance in the original design. Information on how to obtain the Add Health data files is available on the Add Health website: (http://www.cpc.unc.edu/addhealth). We are grateful to the Carolina Population Center (R24 HD050924) for general support.

\section{List of abbreviations and acronyms}

$\begin{array}{ll}\text { ADA } & \text { American Diabetes Association } \\ \text { ICC } & \text { Intraclass correlation coefficient } \\ \text { Add Health } & \text { National Longitudinal Study of Adolescent Health } \\ \text { NHANES } & \text { National Health and Nutrition Examination Survey }\end{array}$

\section{References}

1. American Diabetes Association. Economic Costs of Diabetes in the U.S. in 2012. Diabetes Care. 2013; 36(4):1033-46. [PubMed: 23468086]

2. Rhodes ET, Prosser LA, Hoerger TJ, Lieu T, Ludwig DS, Laffel LM. Estimated morbidity and mortality in adolescents and young adults diagnosed with Type 2 diabetes mellitus. Diabetic Medicine. 2012; 29(4):453-63. [PubMed: 22150528]

3. Fletcher JM, Richards MR. Diabetes's 'Health Shock' To Schooling And Earnings: Increased Dropout Rates And Lower Wages And Employment In Young Adults. Health Affairs. 2012; 31(1): 27-34. [PubMed: 22232091]

4. Roper NA, Bilous RW, Kelly WF, Unwin NC, Connolly VM. Excess mortality in a population with diabetes and the impact of material deprivation: longitudinal, population based study. BMJ. 2001; 322:1389-93. [PubMed: 11397742]

5. Narayan KM, Boyle JP, Thompson TJ, Sorensen SW, Williamson DF. Lifetime risk for diabetes mellitus in the United States. JAMA. 2003; 290:1884-90. [PubMed: 14532317]

6. Dall TM, Zhang Y, Chen YJ, Quick WW, Yang WG, Fogli J. The Economic Burden Of Diabetes. Health Affairs. 2010; 29(2):297-303. [PubMed: 20075080] 
7. Romero CX, Romero TE, Shlay JC, Ogden LG, Dabelea D. Changing Trends in the Prevalence and Disparities of Obesity and Other Cardiovascular Disease Risk Factors in Three Racial/Ethnic Groups of USA Adults. Advances in Preventive Medicine. 2012:1-8.

8. Cheung BMY, Ong KL, Cherny SS, Sham P-C, Tso AWK, Lam KSL. Diabetes Prevalence and Therapeutic Target Achievement in the United States, 1999 to 2006. The American Journal of Medicine. 2009; 122(5):443-53. [PubMed: 19375554]

9. Ong KL, Cheung BM, Wong LY, Wat N, Tan KC, Lam KS. Prevalence, treatment, and control of diagnosed diabetes in the US National Health and Nutrition Examination Survey 1999-2004. Annals of epidemiology. 2008; 18(3):222-9. [PubMed: 18201902]

10. Centers for Disease Control and Prevention. National Diabetes Statistics Report: Estimates of Diabetes and Its Burden in the United States, 2014. Atlanta, GA: U.S. Department of Health and Human Services; 2014.

11. Add Health. Publications: UNC Carolina Population Center. Aug 1. 2014 Available from: http:// www.cpc.unc.edu/projects/addhealth/publications

12. Liang W, Chikritzhs T. Alcohol Consumption during Adolescence and Risk of Diabetes in Young Adulthood. BioMed Research International. 2014; 2014:6.

13. Wickrama T, Merten MJ, Wickrama KAS. Early community influence on young adult physical health: Race/ethnicity and gender differences. Advances in Life Course Research. 2012; 17(1):2533.

14. Harris KM. An integrative approach to health. Demography. 2010; 47(1):1-22. [PubMed: 20355681]

15. National Institute of Aging, Division of Behavioral and Social Research. Workshop Summary Report; NIA Workshop on Harmonization Strategies for Behavioral, Social Science, and Genetic Research; November 29-30, 2011; Bethesda, Maryland. 2011.

16. McDade TW. Development and validation of assay protocols for use with dried blood spot samples. American Journal of Human Biology. 2014; 26(1):1-9. [PubMed: 24130128]

17. Crimmins, E.; Faul, J.; Ki, Kim J.; Guyer, H.; Langa, K.; Ofstedal, MB., et al. Documentation of Biomarkers in the 2006 and 2008 Health and Retirement Study 2013. Nov 2. 2013 Available from: http://hrsonline.isr.umich.edu/sitedocs/userg/Biomarker2006and2008.pdf

18. Harris, KM.; Halpern, CT.; Whitsel, E.; Hussey, J.; Tabor, J.; Entzel, P., et al. The National Longitudinal Study of Adolescent Health: Research Design [WWW document] 2009. Mar 20. 2010 Available from: http://www.cpc.unc.edu/projects/addhealth/design

19. Whitsel, EA.; Tabor, JW.; Nguyen, QC.; Cuthbertson, CC.; Wener, MH.; Potter, AJ., et al. Add Health Wave IV Documentation: Measures of Glucose Homeostasis 2012. Jul 14. 2012 Available from: http://www.cpc.unc.edu/projects/addhealth/data/guides/

20. Fleiss, JL. The design and analysis of clinical experiments. New York: Wiley; 1986.

21. American Diabetes Association. Diagnosis and Classification of Diabetes Mellitus. Diabetes Care. 2013; 36(Supplement 1):S67-S74. [PubMed: 23264425]

22. American Diabetes Association. Standards of Medical Care in Diabetes-2014. Diabetes Care. 2014; 37(Supplement 1):S14-S80. [PubMed: 24357209]

23. U.S. Department of Health and Human Services, Public Health Service, National Institutes of Health, National Heart L, and Blood Institute. The Practical Guide: Identification, Evaluation, and Treatment of Overweight and Obesity in Adults. 2000.

24. Department of Health and Human Services and the Department of Agriculture. Dietary Guidelines for Americans 2005. Dec 1.2010 2005 Available from: http://www.health.gov/dietaryguidelines/ dga2005/document/.

25. Marshall MM, Kirk GD, Caporaso NE, McCormack MC, Merlo CA, Hague JC, et al. Tobacco use and nicotine dependence among HIV-infected and uninfected injection drug users. Addictive Behaviors. 2011; 36(1-2):61-7. [PubMed: 20875704]

26. Olthuis J, Zamboanga B, Ham L, Van Tyne K. The Utility of a Gender-Specific Definition of Binge Drinking on the AUDIT. Journal of the American College Health Association. 2011; 59(4): 239-45. 
27. Gordon-Larsen P, McMurray RG, Popkin BM. Adolescent physical activity and inactivity vary by ethnicity: The National Longitudinal Study of Adolescent Health. The Journal of Pediatrics. 1999; 135(3):301-6. [PubMed: 10484793]

28. Jeppsson JO, Jerntorp P, Almër LO, Persson R, Ekberg G, Sundkvist G. Capillary blood on filter paper for determination of HbA1c by ion exchange chromatography. Diabetes Care. 1996; 19(2): 142-5. [PubMed: 8718434]

29. Petersen PH, Jørgensen LGM, Brandslund I, De Fine Olivarius N, Stahl M. Consequences of Bias and Imprecision in Measurements of Glucose and HbA1c for the Diagnosis and Prognosis of Diabetes Mellitus. Scandinavian Journal of Clinical \& Laboratory Investigation. 2005; 65(s240): 51-60. [PubMed: 16112960]

30. Sacks DB, Bruns DE, Goldstein DE, Maclaren NK, McDonald JM, Parrott M. Guidelines and Recommendations for Laboratory Analysis in the Diagnosis and Management of Diabetes Mellitus. Clinical Chemistry. 2002; 48(3):436-72. [PubMed: 11861436]

31. Sacks DB. A1C Versus Glucose Testing: A Comparison. Diabetes Care. 2011; 34(2):518-23. [PubMed: 21270207]

32. Westgard, QC. Desirable Specifications for Total Error, Imprecision, and Bias, derived from intraand inter-individual biologic variation 2014. Jul 8. 2014 Available from: http://westgard.com/ biodatabase1.htm

33. Eckfeldt JH, Chambless LE, Shen YL. Short-term, within-person variability in clinical chemistry test results. Experience from the Atherosclerosis Risk in Communities Study. Archives of Pathology and Laboratory Medicine. 1994; 118(5):496-500. [PubMed: 8192558]

34. Pineda-Tenor D, Laserna-Mendieta EJ, Timón-Zapata J, Rodelgo-Jiménez L, Ramos-Corral R, Recio-Montealegre A, et al. Biological variation and reference change values of common clinical chemistry and haematologic laboratory analytes in the elderly population. Clinical Chemistry and Laboratory Medicine. 2013; 51(4):851-62. [PubMed: 23518452]

35. Ricos, C.; Alvarez, V.; Cava, F.; Garcia-Lario, J.; Hernandez, A.; Jimenez, C., et al. Desirable specifications for imprecision, inaccuracy, and total allowable error, calculated from data on within-subject and between-subject biologic variation (Online database): Westgard QC 2014. Jul 8. 2014 Available from: http://www.westgard.com/biodatabase1.htm

36. Centers for Disease Control and Prevention. National diabetes fact sheet: national estimates and general information on diabetes and prediabetes in the United States, 2011. Atlanta, GA: 2011.

37. CDC. National Diabetes Surveillance System. Atlanta, GA: Department of Health and Human Services, CDC; Available from: http://apps.nccd.cdc.gov/DDTSTRS/default.aspx

38. Kanjilal S, Gregg EW, Cheng YJ, et al. SOcioeconomic status and trends in disparities in 4 major risk factors for cardiovascular disease among us adults, 1971-2002. Archives of Internal Medicine. 2006; 166(21):2348-55. [PubMed: 17130388]

39. Narayan KMV, Boyle JP, Geiss LS, Saaddine JB, Thompson TJ. Impact of Recent Increase in Incidence on Future Diabetes Burden: U.S., 2005-2050. Diabetes Care. 2006; 29(9):2114-6. [PubMed: 16936162]

40. Centers for Disease Control and Prevention (CDC). Diabetes-United States, 2006 and 2010. MMWR. 2013; 62(Suppl 3):97-102.

41. White K, Mondesir FL, Bates LM, Glymour MM. Diabetes Risk, Diagnosis, and Control: Do Psychosocial Factors Predict Hemoglobin A1c Defined Outcomes or Accuracy of Self-reports? Ethnicity and Disease. 2014; 24:19-27. [PubMed: 24620444]

42. Heidenreich PA, Trogdon JG, Khavjou OA, Butler J, Dracup K, Ezekowitz MD, et al. Forecasting the Future of Cardiovascular Disease in the United States: A Policy Statement From the American Heart Association. Circulation. 2011; 123(8):933-44. [PubMed: 21262990]

43. Lloyd-Jones DM, Hong Y, Labarthe D, Mozaffarian D, Appel LJ, Van Horn L, et al. Defining and setting national goals for cardiovascular health promotion and disease reduction: the American Heart Association's strategic Impact Goal through 2020 and beyond. Circulation. 2010; 121(4): 586-613. [PubMed: 20089546]

44. Rosner B, Cook NR, Daniels S, Falkner B. Childhood Blood Pressure Trends and Risk Factors for High Blood Pressure: The NHANES Experience 1988-2008. Hypertension. 2013; 62(2):247-54. [PubMed: 23856492] 
45. Imperatore G, Boyle JP, Thompson TJ, Case D, Dabelea D, Hamman RF, et al. Projections of Type 1 and Type 2 Diabetes Burden in the U.S. Population Aged <20 Years Through 2050: Dynamic modeling of incidence, mortality, and population growth. Diabetes Care. 2012; 35(12): 2515-20. [PubMed: 23173134]

46. Ogden CL, Flegal KM, Carroll MD, Johnson CL. Prevalence and trends in overweight among us children and adolescents, 1999-2000. JAMA. 2002; 288(14):1728-32. [PubMed: 12365956]

47. Nguyen QC, Tabor JW, Entzel PP, Lau Y, Suchindran C, Hussey JM, et al. Discordance in National Estimates of Hypertension Among Young Adults. Epidemiology. 2011; 22(4):532-41. [PubMed: 21610501]

48. Gordon-Larsen P, The NS, Adair LS. Longitudinal trends in obesity in the United States from adolescence to the third decade of life. Obesity (Silver Spring). 2010; 18(9):1801-4. [PubMed: 20035278]

49. Brownstein, N.; Kalsbeek, WD.; Tabor, JW.; Entzel, PP.; Daza, E.; Harris, KM. Non-Response in Wave IV of the National Longitudinal Study of Adolescent Health. Jun 28. 2014 Available from: http://www.cpc.unc.edu/projects/addhealth/data/guides

50. Wang TJ, Massaro JM, Levy D, et al. A risk score for predicting stroke or death in individuals with new-onset atrial fibrillation in the community: The framingham heart study. JAMA. 2003; 290(8): 1049-56. [PubMed: 12941677]

51. Choi HK, Willett WC, Stampfer MJ, Rimm E, Hu FB. Dairy consumption and risk of type 2 diabetes mellitus in men: A prospective study. Archives of Internal Medicine. 2005; 165(9):9971003. [PubMed: 15883237]

52. Folsom AR, Nieto FJ, McGovern PG, Tsai MY, Malinow MR, Eckfeldt JH, et al. Prospective Study of Coronary Heart Disease Incidence in Relation to Fasting Total Homocysteine, Related Genetic Polymorphisms, and B Vitamins: The Atherosclerosis Risk in Communities (ARIC) Study. Circulation. 1998; 98(3):204-10. [PubMed: 9697819]

53. Zhang P, Engelgau MM, Valdez R, Cadwell B, Benjamin SM, Narayan KMV. Efficient Cutoff Points for Three Screening Tests for Detecting Undiagnosed Diabetes and Pre-Diabetes: An economic analysis. Diabetes Care. 2005; 28(6):1321-5. [PubMed: 15920046]

54. Johnson SL, Tabaei BP, Herman WH. The Efficacy and Cost of Alternative Strategies for Systematic Screening for Type 2 Diabetes in the U.S. Population 45-74 Years of Age. Diabetes Care. 2005; 28(2):307-11. [PubMed: 15677784]

55. Ziemer DC, Kolm P, Foster JK, Weintraub WS, Vaccarino V, Rhee MK, et al. Random plasma glucose in serendipitous screening for glucose intolerance: Screening for impaired glucose tolerance study 2. Journal of General Internal Medicine. 2008; 23(5):528-35. [PubMed: 18335280]

56. Ealovega MW, Tabaei BP, Brandle M, Burke R, Herman WH. Opportunistic Screening for Diabetes in Routine Clinical Practice. Diabetes Care. 2004; 27(1):9-12. [PubMed: 14693958]

57. Saudek CD, Herman WH, Sacks DB, Bergenstal RM, Edelman D, Davidson MB. A New Look at Screening and Diagnosing Diabetes Mellitus. Journal of Clinical Endocrinology \& Metabolism. 2008; 93(7):2447-53. [PubMed: 18460560]

58. Selvin E, Zhu H, Brancati FL. Elevated A1C in Adults Without a History of Diabetes in the U.S. Diabetes Care. 2009; 32(5):828-33. [PubMed: 19196895]

59. Bennett CM, Guo M, Dharmage SC. HbA1c as a screening tool for detection of Type 2 diabetes: a systematic review. Diabetic Medicine. 2007; 24(4):333-43. [PubMed: 17367307]

60. Selvin E, Steffes MW, Gregg E, Brancati FL, Coresh J. Performance of A1C for the Classification and Prediction of Diabetes. Diabetes Care. 2011; 34(1):84-9. [PubMed: 20855549]

61. Boyle J, Thompson T, Gregg E, Barker L, Williamson D. Projection of the year 2050 burden of diabetes in the US adult population: dynamic modeling of incidence, mortality, and prediabetes prevalence. Population Health Metrics. 2010; 8(1):29. [PubMed: 20969750] 
Table 1

Characteristics of the Add Health Wave IV (2008) Participants Aged 24-32 years

\begin{tabular}{|c|c|c|}
\hline & $\mathrm{n}^{a}$ & $\%(95 \% \mathrm{CI})^{b}$ \\
\hline Age, Mean(SD) & 13542 & $28.3(1.8)$ \\
\hline Females & 7315 & $50.2(48.9,51.4)$ \\
\hline \multicolumn{3}{|l|}{ Race/Ethnicity } \\
\hline White, Non-Hispanic & 7307 & $66.6(60.8,72.0)$ \\
\hline Black, Non-Hispanic & 2643 & $14.3(10.9,18.6)$ \\
\hline Asian/Pacific Islander, non-Hispanic & 748 & $2.9(1.8,4.6)$ \\
\hline Other Race/Multiracial & 828 & $5.1(4.3,6.1)$ \\
\hline Mexican-American & 908 & $5.9(4.1,8.6)$ \\
\hline Other Hispanic & 1053 & $5.1(3.5,7.5)$ \\
\hline \multicolumn{3}{|l|}{ Nativity } \\
\hline U.S. Born & 12541 & $94.8(92.9,96.1)$ \\
\hline Foreign-Born & 995 & $5.3(3.9,7.1)$ \\
\hline \multicolumn{3}{|l|}{ Education } \\
\hline 4-yr college or greater & 4218 & $29.4(26.3,32.6)$ \\
\hline Some college/AA degree & 6073 & $43.8(42.1,45.4)$ \\
\hline H.S. graduate/GED & 2201 & $17.8(16.1,19.6)$ \\
\hline $0-11$ years & 1049 & $9.0(7.8,10.5)$ \\
\hline Uninsured & 2817 & $22.4(21.0,23.8)$ \\
\hline Currently pregnant (among females) & 455 & $3.0(2.7,3.4)$ \\
\hline History of diabetes & 392 & $2.6(2.3,3.1)$ \\
\hline Diabetes medications & 194 & $1.3(1.1,1.6)$ \\
\hline Fasting $\geq 8$ hours & 2221 & $16.3(15.1,17.7)$ \\
\hline \multicolumn{3}{|l|}{ BMI } \\
\hline Underweight/Normal & 4225 & $33.1(31.6,34.7)$ \\
\hline Overweight & 3848 & $29.4(28.2,30.6)$ \\
\hline Obese Class I & 2391 & $18.7(17.7,19.6)$ \\
\hline Obese Class II/III & 2475 & $18.8(17.6,20.2)$ \\
\hline Abdominal obesity $c$ & 6397 & $48.1(46.5,49.8)$ \\
\hline \multicolumn{3}{|l|}{ Fast food intake (times a week) } \\
\hline None & 3084 & $23.3(21.4,25.3)$ \\
\hline 2 or less & 5854 & $43.1(41.9,44.3)$ \\
\hline 3 or more & 4596 & $33.6(31.6,35.6)$ \\
\hline \multicolumn{3}{|l|}{ Moderate to vigorous recreational activity } \\
\hline $5+$ times a week & 7196 & $53.4(51.9,54.9)$ \\
\hline 1-4 times/week & 4242 & $31.9(30.8,33.0)$ \\
\hline None & 2094 & $14.7(13.7,15.7)$ \\
\hline \multicolumn{3}{|l|}{ Smoking } \\
\hline None in past 30 days & 8575 & $60.8(58.8,62.7)$ \\
\hline
\end{tabular}




\begin{tabular}{lcc}
\hline & $\mathbf{n}^{\boldsymbol{a}}$ & $\boldsymbol{\%}(\mathbf{9 5 \%} \mathbf{C I})^{\boldsymbol{b}}$ \\
\cline { 2 - 3 } & 1900 & $14.1(13.3,15.1)$ \\
Less than Daily & 2957 & $25.1(23.2,27.1)$ \\
Daily & & \\
Binge drinking & 7121 & $49.8(47.6,52.0)$ \\
$\quad$ None & 4857 & $37.9(36.1,39.7)$ \\
< Weekly & 1515 & $12.4(11.3,13.5)$ \\
2Weekly & & \\
Measurement session & 6075 & $45.1(43.5,46.7)$ \\
Morning & 4239 & $32.1(31.0,33.2)$ \\
Afternoon & 3167 & $22.9(21.5,24.3)$ \\
Evening & & \\
\hline
\end{tabular}

${ }^{a}$ Restricted to participants with HbAlc or glucose data

${ }^{b}$ Percentages (95\% confidence interval) weighted to be representative of U.S. adolescents in grades 7-12 during the 1994-1995 school year

${ }^{c}$ Abdominal obesity defined as $>102 \mathrm{~cm}$ (men) and $>88 \mathrm{~cm}$ (women, excluding pregnant women) 


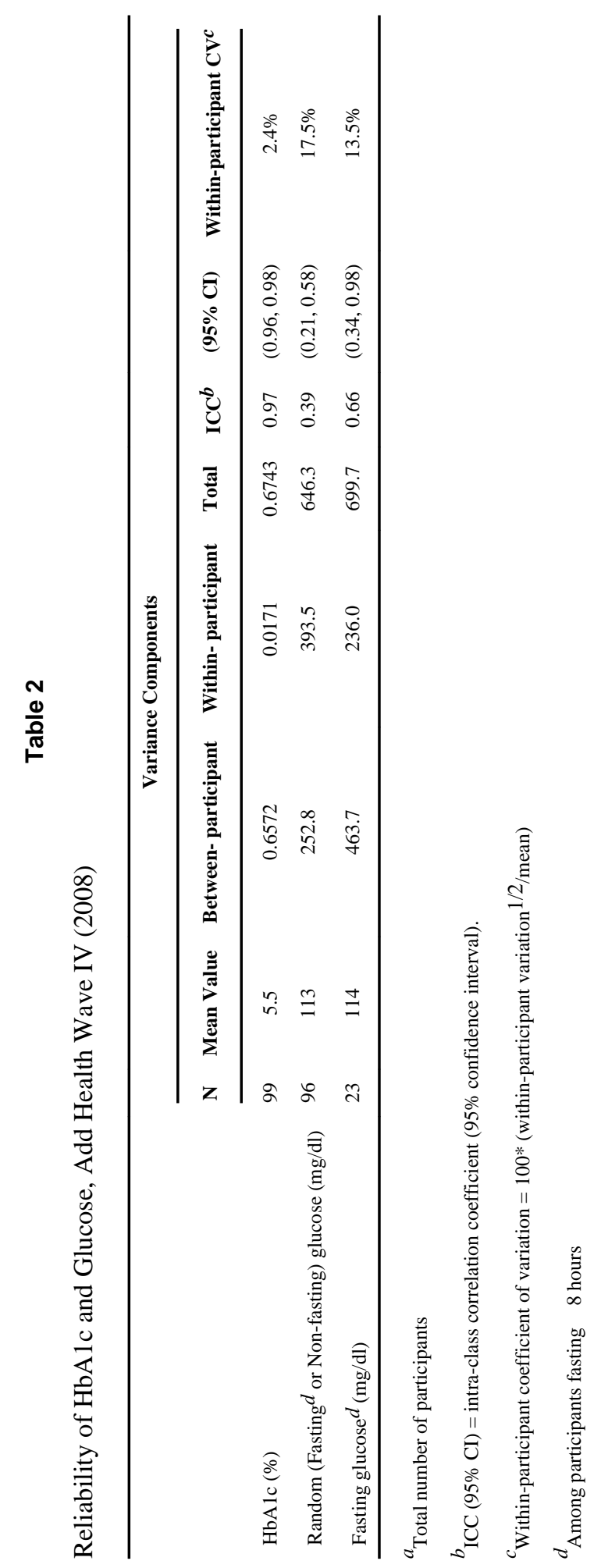




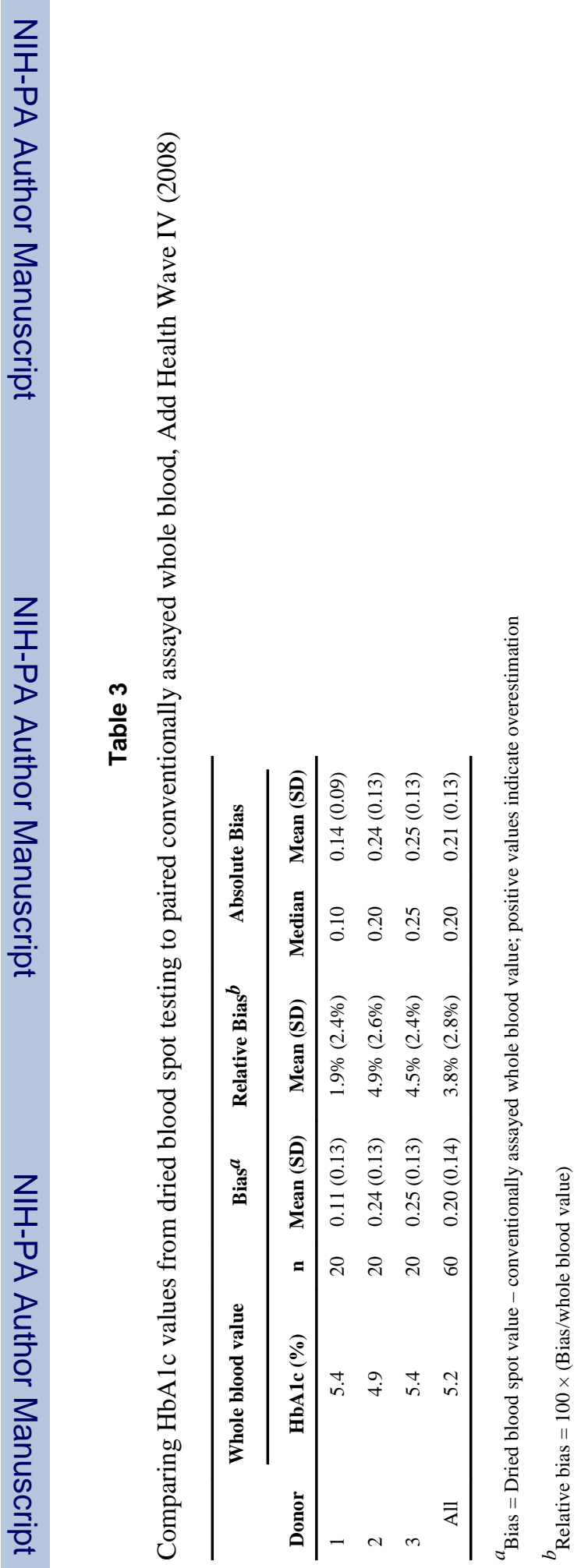




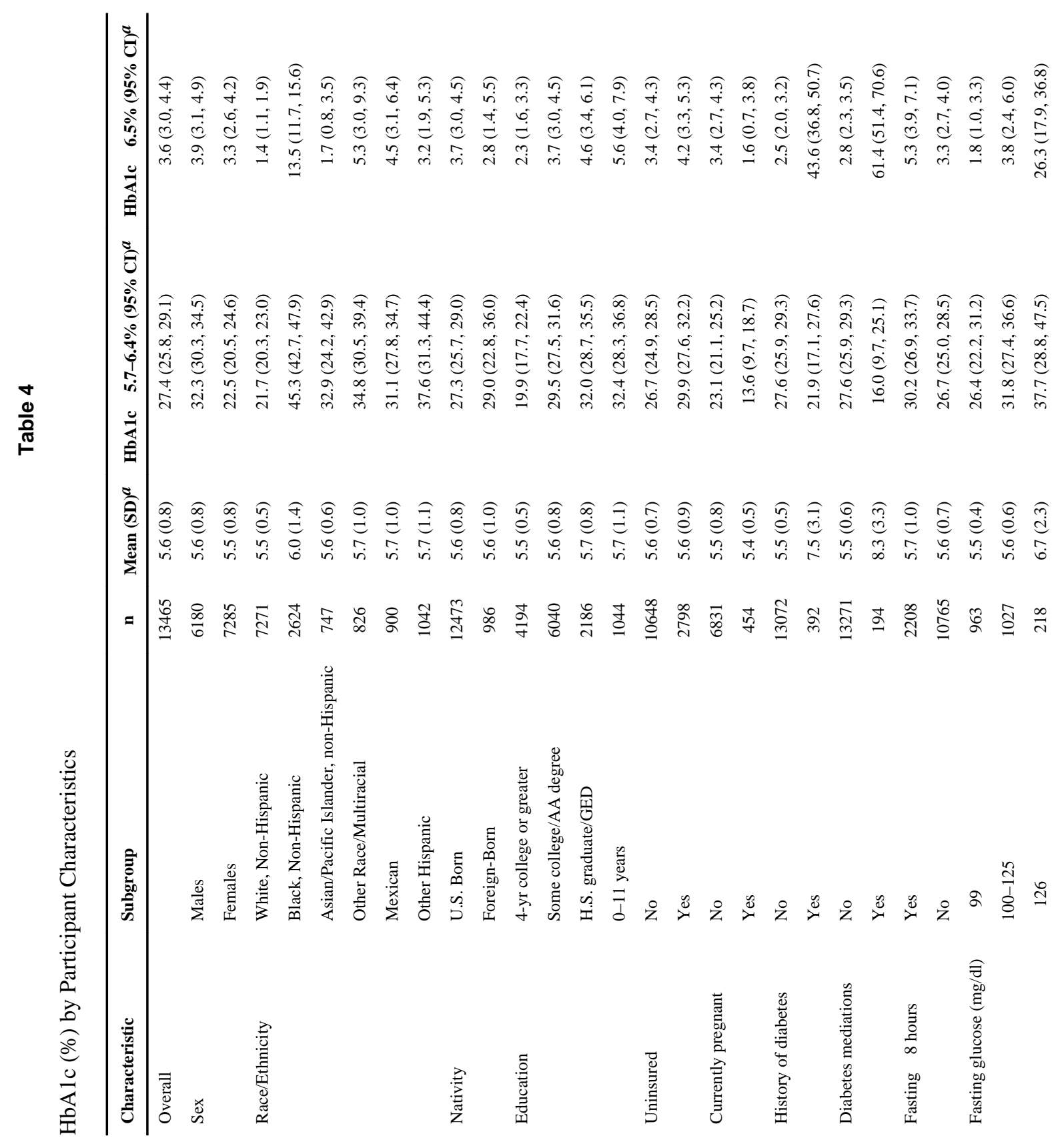




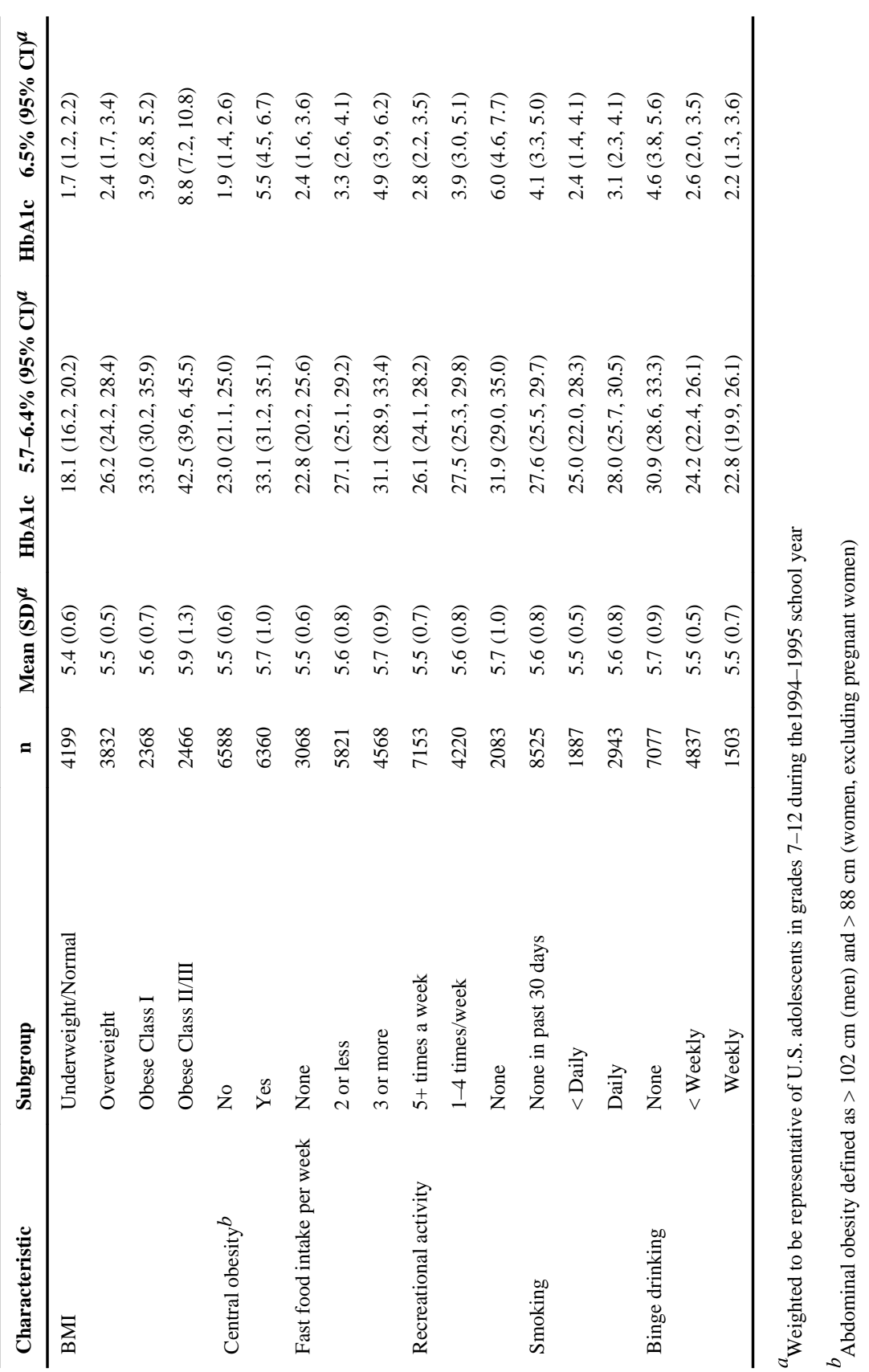

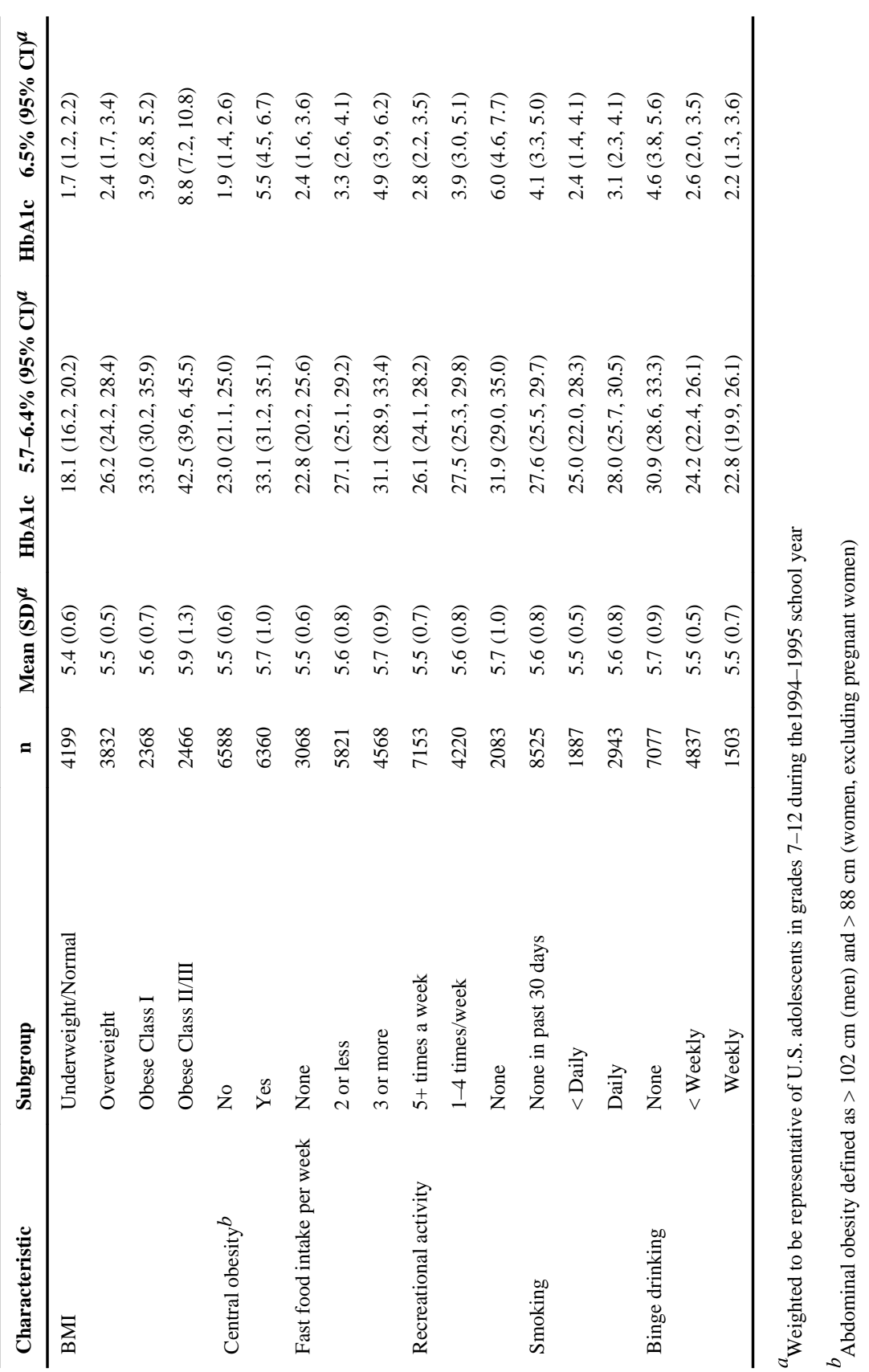

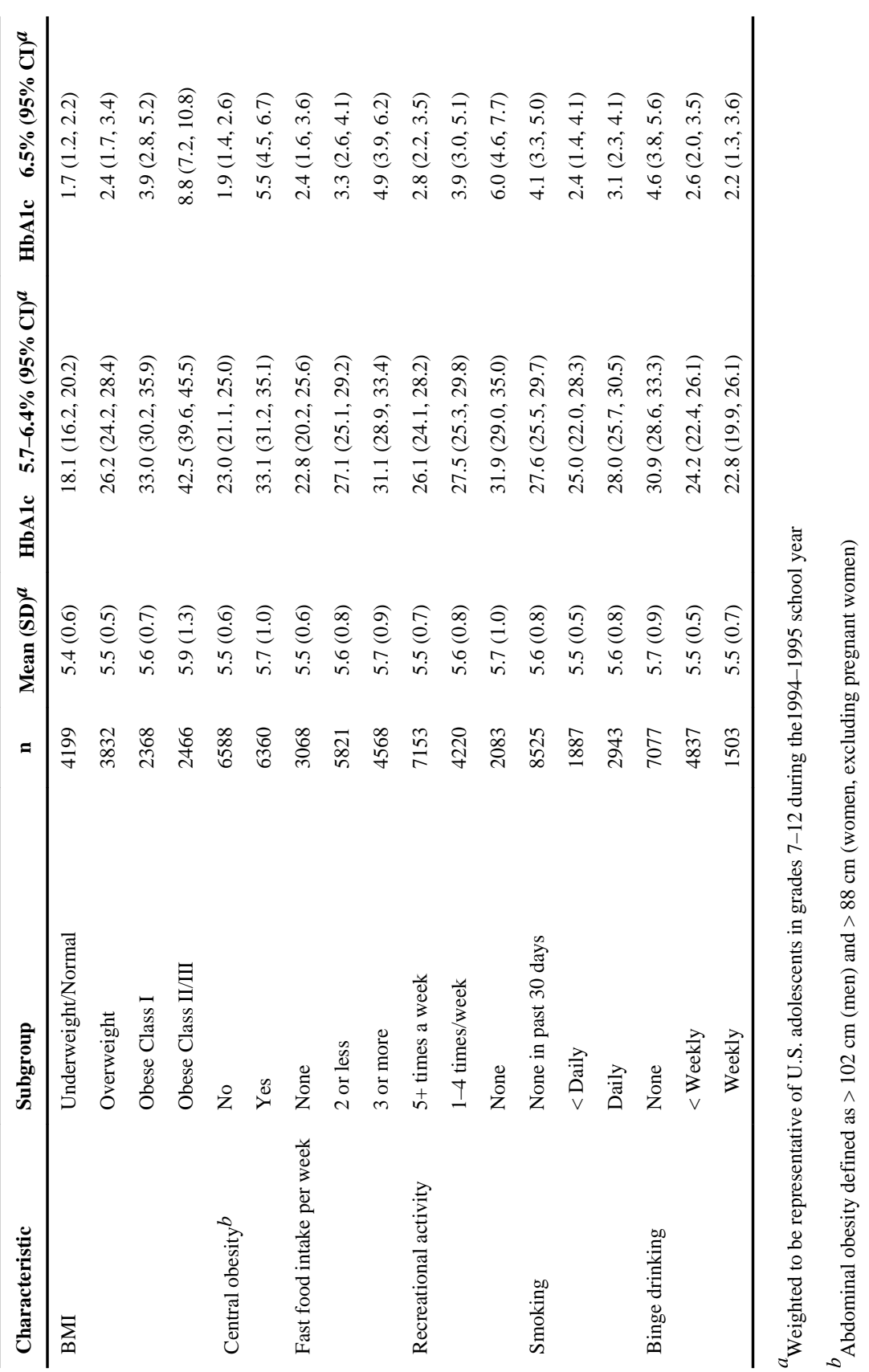


Table 5

High Glucose (mg/dL) Prevalence by Participant Characteristics

\begin{tabular}{|c|c|c|c|}
\hline Characteristic & Subgroup & $\mathbf{n}$ & $\begin{array}{r}\text { Non-Fasting Glucose } \geq 200 \text { or Fasting Glucose } \geq 126 \mathrm{mg} / \mathrm{dl} \\
\%(95 \% \mathrm{CI})^{a}\end{array}$ \\
\hline Overall & & 13112 & $2.5(2.2,2.9)$ \\
\hline \multirow[t]{2}{*}{ Sex } & Males & 5972 & $3.5(2.9,4.2)$ \\
\hline & Females & 7140 & $1.6(1.2,2.2)$ \\
\hline \multirow[t]{6}{*}{ Race/Ethnicity } & White, non-Hispanic & 7092 & $2.0(1.7,2.5)$ \\
\hline & Black, non-Hispanic & 2518 & $3.4(2.5,4.7)$ \\
\hline & Asian/Pacific Islander, non-Hispanic & 739 & $1.2(0.5,2.7)$ \\
\hline & Other Race/Multiracial & 808 & $4.2(2.1,8.3)$ \\
\hline & Mexican & 881 & $4.2(2.4,7.3)$ \\
\hline & Other Hispanic & 1019 & $3.6(2.3,5.4)$ \\
\hline \multirow[t]{2}{*}{ Nativity } & U.S. Born & 12319 & $2.5(2.1,2.9)$ \\
\hline & Foreign-Born & 792 & $1.9(0.9,4.0)$ \\
\hline \multirow[t]{4}{*}{ Education } & 4-yr college or greater & 4096 & $1.5(1.0,2.2)$ \\
\hline & Some college/AA degree & 5883 & $2.8(2.3,3.4)$ \\
\hline & H.S. graduate/GED & 2120 & $3.1(2.1,4.6)$ \\
\hline & $0-11$ years & 1013 & $3.5(2.3,5.2)$ \\
\hline \multirow[t]{2}{*}{ Uninsured } & No & 10374 & $2.3(1.9,2.8)$ \\
\hline & Yes & 2720 & $3.3(2.5,4.5)$ \\
\hline \multirow[t]{2}{*}{ Currently pregnant } & No & 12664 & $2.6(2.2,3.0)$ \\
\hline & Yes & 448 & $1.2(0.4,3.4)$ \\
\hline \multirow[t]{2}{*}{ History of diabetes } & No & 12728 & $1.8(1.5,2.2)$ \\
\hline & Yes & 383 & $27.8(22.2,34.2)$ \\
\hline \multirow[t]{2}{*}{ Diabetes medications } & No & 12923 & $2.0(1.7,2.4)$ \\
\hline & Yes & 189 & $38.0(29.8,47.0)$ \\
\hline \multirow[t]{2}{*}{ Fasting $\geq 8$ hours } & Yes & 2221 & $10.3(8.6,12.2)$ \\
\hline & No & 10778 & $1.0(0.7,1.3)$ \\
\hline \multirow[t]{3}{*}{$\mathrm{HbA1c}(\%)$} & $\leq 5.6$ & 8674 & $1.0(0.7,1.4)$ \\
\hline & $5.7-6.4$ & 3790 & $2.5(1.9,3.3)$ \\
\hline & $\geq 6.5$ & 570 & $31.6(25.1,38.8)$ \\
\hline \multirow[t]{4}{*}{ BMI } & Underweight/Normal & 4069 & $1.4(1.0,1.9)$ \\
\hline & Overweight & 3715 & $1.9(1.3,2.7)$ \\
\hline & Obese Class I & 2324 & $3.0(2.1,4.1)$ \\
\hline & Obese Class II/III & 2413 & $5.2(4.0,6.7)$ \\
\hline \multirow[t]{2}{*}{ Central obesity $b$} & No & 6377 & $1.7(1.3,2.2)$ \\
\hline & Yes & 6226 & $3.4(2.8,4.2)$ \\
\hline \multirow[t]{3}{*}{ Fast food intake per week } & None & 2987 & $2.0(1.5,2.8)$ \\
\hline & 2 or less & 5678 & $2.3(1.8,3.0)$ \\
\hline & 3 or more & 4439 & $3.1(2.5,3.9)$ \\
\hline Recreational activity & $5+$ times a week & 6954 & $2.0(1.6,2.6)$ \\
\hline
\end{tabular}




\begin{tabular}{lllr}
\hline Characteristic & Subgroup & n & $\begin{array}{r}\text { Non-Fasting Glucose } \mathbf{2 0 0} \text { or Fasting Glucose } \mathbf{2 1 2 6} \mathbf{~ m g} / \mathbf{d l} \\
\mathbf{\%}(\mathbf{9 5 \%} \mathbf{C I})\end{array}$ \\
\hline \multirow{3}{*}{ Smoking } & $1-4$ times/week & 4131 & $2.9(2.3,3.6)$ \\
& None & 2016 & $3.6(2.6,4.9)$ \\
& None in past 30 days & 8301 & $2.6(2.1,3.2)$ \\
Binge drinking & L Daily & 1834 & $2.3(1.6,3.4)$ \\
& Daily & 2873 & $2.4(1.8,3.3)$ \\
& None & 6896 & $2.7(2.2,3.3)$ \\
& $<$ Weekly & 4715 & $2.1(1.6,2.8)$ \\
& $\geq$ Weekly & 1456 & $2.9(1.8,4.8)$ \\
\hline
\end{tabular}

${ }^{a}$ Weighted to be representative of U.S. adolescents in grades 7-12 during the 1994-1995 school year

${ }^{b}$ Abdominal obesity defined as $>102 \mathrm{~cm}$ (men) and $>88 \mathrm{~cm}$ (women, excluding pregnant women) 


\section{Table 6}

\section{Diabetes and Its Medical Management}

\begin{tabular}{|c|c|c|}
\hline Diabetes definition & $\mathbf{N}$ & $\%(95 \% \mathrm{CI})$ \\
\hline \multicolumn{3}{|l|}{ Self-report and medication inventory } \\
\hline Medication use $b$ & 14751 & $1.3(1.0,1.6)$ \\
\hline History $c$ & 14749 & $2.6(2.2,3.0)$ \\
\hline History or medication & 14749 & $2.9(2.5,3.3)$ \\
\hline \multicolumn{3}{|l|}{ HbAlc, self-report, medication inventory } \\
\hline $\operatorname{High}^{d} \mathrm{HbA} 1 \mathrm{c}$ & 13465 & $3.6(3.0,4.4)$ \\
\hline $\mathrm{High}^{d} \mathrm{HbA} 1 \mathrm{c}$, history or medication & 13464 & $5.4(4.7,6.3)$ \\
\hline \multicolumn{3}{|l|}{ Glucose, self-report, medication inventory } \\
\hline High $^{d}$ glucose & 13111 & $2.5(2.2,2.9)$ \\
\hline $\mathrm{High}^{d}$ glucose, history or medication & 13111 & $4.8(4.3,5.3)$ \\
\hline \multicolumn{3}{|l|}{ Comprehensive } \\
\hline Diabetes (High glucose, high HbA1c, history or medication) & 13034 & $6.8(6.0,7.7)$ \\
\hline \multicolumn{3}{|l|}{ Medical management } \\
\hline Among those with diabetes, percent aware (i.e., diagnosed) & 972 & $38.9(33.8,44.3)$ \\
\hline Among those aware, percent treated with medications & 383 & $37.6(30.4,45.5)$ \\
\hline Among those aware, percent controlled (i.e., $\mathrm{HbA} 1 \mathrm{c}<7 \%$ ) & 383 & $64.0(56.9,70.5)$ \\
\hline
\end{tabular}

Missingness varies due to availability of variables used to define diabetes

${ }^{a}$ Weighted to be representative of U.S. adolescents in grades 7-12 during the 1994-1995 school year

${ }^{b}$ Anti-diabetic medication use

${ }^{c}$ History of being told by a doctor or healthcare professional that you have diabetes (if female, outside of pregnancy).

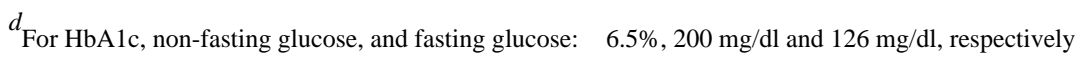

